\title{
MEDIA GAME EDUKASI BERBASIS BUDAYA UNTUK PEMBELAJARAN PENGENALAN BILANGAN PADA ANAK USIA DINI
}

\author{
Dwi Songgo Panggayudi ${ }^{1}$, Wardah Suweleh ${ }^{2}$, Pramudana Ihsan ${ }^{3}$ \\ 1,2,3 Universitas Muhammadiyah Surabaya \\ dwisonggopanggayudi@gmail.com¹, wardahsuweleh28@gmail.com²
}

\begin{abstract}
ABSTRAK
Matematika merupakan ilmu pengetahuan yang perkembangannya dipengaruhi oleh konteks sosial budaya. Oleh karena itu, sangat mungkin pembelajaran matematika dengan mengintegrasikannyadengan budaya. Pengintegrasian ini berupaya untuk meningkatkan mutu atau kualitas pendidikan dalam rangka menghadapi tantangan global, salah satunya dengan melakukan pembelajaran matematika berbasis budaya dengan memanfaatkan teknologi. Potensi teknologi komputer sebagai media pembelajaran dalam meningkatkan kualitas pembelajaran matematika tentang pengenalan bilangan, sehingga perlu adanya pengembangan media pembelajaran game edukasi berbasis budaya dengan menggunakan aplikasi Adobe Flash CS6 Professional. Game edukasi merupakan suatu teknologi yang dapat dimanfaatkan sebagai media pembelajaran inovatif guna menunjang kegiatan belajar mengajar. Sehingga, pemanfaatan game dalam dunia pendidikan merupakan suatu keniscayaan, dimana akan memberikan dampak yang positifdalam proses pembelajaran. Tujuan penelitian dan pengembangan ini adalah untuk menghasilkan media pembelajarangame edukasi berbasis budaya yang dapat digunakan sebagai media pembelajaran alternatif dalammengatasi kesulitan belajar siswa/i PAUD, serta sebagai cara inovatif untuk mengenalkan budaya Indonesia sejak dini. Jenis penelitian ini tergolong penelitian dan pengembangan. Prosedur penelitian dan pengembangan diadaptasi dari Thiagarajan dengan 4D yaitu Define, Design, Development and Dissemination. Teknik pengambilan data menggunakan wawancara, studi dokumentasi dan angket. Media Pembelajaran game edukasi valid dengan ratarata persentase $83,50 \%$, praktis dengan persentase $88,60 \%$, dan efektif dengan rata-rata persentase $88,23 \%$ serta hasil perhitungan sumbangan keberhasilan penggunaan Media Pembelajaran game edukasi pada uji coba sebesar 90,44\% (skala kecil) dan $85,19 \%$ (skala besar). Selain itu, untuk mengukur efektivitas media tersebut juga dapat dilihat berdasarkan skor pencapaian hasil belajar siswa yang menunjukkan rata-rata di atas KKM 75 (dalam hal ini 7,5). Secara keseluruhan, rataratanya di atas 7, meskipun terdapat 2 siswa pada uji coba skala kecil dan 3 siswa pada uji coba skala besar yang mendapat skor di bawah 7 .
\end{abstract}

Kata kunci: integrasi, budaya, game edukasi, penelitian pengembangan

\begin{abstract}
Mathematics is a science whose development is influenced by socio-cultural context. Therefore, it is possible to study mathematics by integrating it with culture. This integration seeks to improve the quality or quality of education in order to face global challenges, one of them by doing cultural-based mathematics learning using technology. Potential computer technology as a learning media in improving the quality of mathematics learning about the introduction of numbers, so the need for the development of educational media-based educational game culture using Adobe Flash CS6 Professional application. Educational game is a technology that can be utilized as an innovative learning media to support teaching and learning activities. Thus, the use of games in the world of education is a necessity, which will provide a positive impact in the learning process. The purpose of this research and development is to produce cultural-based educational learning media that can be used as an alternative learning media in overcoming students' learning difficulties, and as an innovative way to introduce Indonesian culture from an early age. This type of research is classified as research and development. The research and development procedure adapted from Thiagarajan with 4D is Define, Design, Development and Dissemination. Techniques of data collection using interviews, documentation studies and questionnaires. Media Learning educational game valid with average percentage $83,50 \%$, practical
\end{abstract}


with percentage $88,60 \%$, and effective with mean percentage $88,23 \%$ and result of calculation of success contribution of media use Learning educational game at trial $90,44 \%$ (small scale) and 85.19\% (large scale). In addition, to measure the effectiveness of these media can also be seen based on achievement scores of student learning outcomes that show above average KKM 75 (in this case 7.5). Overall, the average was above 7, although there were 2 students on a small-scale trial and 3 students on a large-scale trial that scored below 7 .

Keywords: integration, culture, educational games, research development

\section{PENDAHULUAN}

Salah satu cabang kajian matematika adalah geometri dengan focus kajiannya yaitu mempelajari bentuk atau bangun suatu objek beserta ukurannya. Diantara kajian yang ada dalam geometri yaitu terkait dengan definisi-definisi, postulat-postulat, aksioma-aksioma, serta dalil-dalil yang dikemukakan oleh Euclid yang kemudian lebih familiar dengan geometri Euclid.

Pendidikan merupakan faktor dominan untuk membawa sumberdaya manusia mengikuti perkembangan zaman yang selalu berubah dan penuh kebaruan (In'am, 2015). Sedangkan menurut Suprapti (2015) Pendidikan merupakan investasi sangat strategis dalam mempersiapkan sumberdaya manusia yang berkualitas serta melestarikan sistem nilai yang berkembang dalam kehidupan melalui transfer ilmu pengetahuan (transfer of knowledge). Salah satu cabang dari ilmu pengetahuan adalah matematika yang merupakan ilmu dasar yang sangat penting dalam pengembangan sain dan teknologi (Wulandari, 2014; Laksana, 2013).

Matematika merupakan ilmu pengetahuan yang perkembangannya juga dipengaruhi oleh konteks sosial budaya. Oleh karena itu, sangat mungkin membelajarkan matematika dengan mengintegrasikannyadengan budaya (Danoebroto, 2012). Salah satunya dengan mengintegrasikan budaya dengan matematika. Menurut Muslimin dkk (2012) kearifan budaya local (local jenius) sangat penting dalam menunjang proses pembelajaran, maka perlu dieksplorasi lebih jauh khasanah budaya di Indonesia dalam menunjang pembelajaran matematika.

Perkembangan teknologi informasi dewasa initelah mampu mengemas kondisi dan realitas pembelajaran menjadi lebih menarik dan memberikan pengondisian secara adaptif dalam proses pembelajaran dimanapun berada (Darmawan, 2012), serta penggunaan teknologi dalam pembelajaran pun lebih 
efektif dibanding pembelajaran yang konvensional (Serin, 2011).Adanya keistimewaan tersebut, khususnya komputer, guru seharusnya tidak perlu lagi khawatir. Dalam penggunaannya, terdapat beberapa model pembelajaran berbantuan komputer yang menarik, salah satunya adalah model permainan (games) (Darmawan, 2012).

Model permainan (games) dikembangkan berdasarkan pembelajaran yang menyenangkan, dimana peserta didik akan dihadapkan pada beberapa petunjuk dan aturan permainan (Sanjaya, 2012; Darmawan, 2012). Panagiotakopoulos (2011) menuturkan bahwasiswa akan memperoleh manfaat dari penggunaan game edukasi dimana mereka akan merasa senang dan gembira dalam belajar matematika,karena mereka akan berhitung sambil bermain. Sari dkk (2012) pun menambahkan bahwa gamemempunyai pesona adiktif yang dapat membuat pemainnya "kecanduan". Berdasarkan fenomena inilah, perlu berbagai inovasi kreatif dalam menciptakangameyang memuat konten pendidikan sebagai media pembelajaran sehinggadapat dimanfaatkan di dunia pendidikaan guna mendukung kegiatan belajar mengajar dan menarik minat atau motivasi belajar siswa.

Melihat betapa berpotensinya teknologi komputer sebagai media pembelajaran dalam meningkatkan kualitas pembelajaran matematika dan betapa penting pembelajaran pengenalan bilangan, maka dalam penelitian ini akan dilakukan suatu pengembangan produk media pembelajaran game edukasi berbasis budaya dengan menggunakan aplikasi Adobe Flash CS6 Professional. Media pembelajaran ini nantinya akan dikemas dalam bentuk Compact Disc (CD) yang dapat digunakan oleh guru dalam pembelajaran di kelas menggunakan komputer. Berdasarkan pemaparan inilah, maka penting untuk dilakukan suatu penelitian dan pengembangan yang berjudul "Media Game Edukasi Berbasis Budaya untuk Pembelajaran Pengenalan Bilangan pada anak Usia Dini”. 


\section{Rumusan Masalah}

Berdasarkan latar belakang tersebut, dapat dirumuskan masalahsebagai berikut: "Bagaimanakah proses dan hasil pengembanganmedia pembelajaran Game Edukasi sebagai media pembelajaran untuk mengatasi kesulitan siswa/i Sekolah Pendidikan Anak Usia Dini (PAUD) dalam pelaksanaan pembelajaran Bilangan?"

\section{Tinjauan Pustaka}

Kata media adalah bentuk jamak dari medium yang berasal dari bahasa latin medius yang berarti “tengah". Dalam bahasa Indonesia kata “medium”dapat diartikan sebagai antara atau selang. Dengan artian media mengarah pada sesuatu yang mengantar meneruskan informasi (pesan) antara sumber (pemberi pesan) dan penerima pesan yang bertujuan instruksional atau mengandung maksud-maksud pengajaran (Arsyad 2009; Sadiman dkk, 2010; Hasrul, 2011; Triyanto, 2013).

Media memiliki peranan penting dalam proses pembelajaran (Ali, 2009), keberadaan media pembelajaran mampu membangkitkan minat belajar, motivasi serta membawa pengaruh psikologis bagi siswa dalam proses belajar mengajar. Media dalampembelajaran memiliki fungsi sebagai alat bantuuntuk memperjelas pesan yang disampaikan guru (Safitri dkk, 2013).

Peranan media dalam proses mendapatkan pengalaman belajar bagi siswa, Edgar Dale melukiskannya dalam sebuah kerucut yang kemudian dinamakan Kerucut Pengalaman Dale (Sanjaya, 2012). Untuk lebih jelasnya dapat dilihat pada gambar Kerucut Pengalaman Dale sebagai berikut (Rusman, 2012; Sanjaya, 2012) :

Pemerolehan pengetahuan dan keterampilan terjadi karena interaksi antara pengalaman baru dengan pengalaman lama, ada tiga tingkatan modus belajar menurut Bruner (Arsyad, 2009). Pertama adalah pengalaman langsung (enactive)merupakan suatu tahap pengetahuan yang dipelajari secara aktif dengan menggunakan benda-benda kongkrit atau menggunakan situasi yang nyata, kedua adalah pengalaman pictorial/gambar (iconic) merupakan tahap pengetahuan yang direpresentasikan dalam bentuk bayangan visual (visual imagery), gambar atau piagam yang menggambarkan kegiatan kongkrit atau situasi kongkrit yang 
terdapat pada tahap enactive. Ketiga pengalaman abstract (symbolic) yaitu suatu tahap pengetahuan yang direpresentasikan dengan menggunakan simbol-simbol abstrak yang dipakai berdasarkan kesepakatan yang bersangkutan baik berupa simbol verbal lambang matematika maupun lambang-lambang abstrak lainnya. Ketiga tingkat pengalaman ini saling berinteraksi untuk memperoleh pengalaman (pengetahuan, keterampilan atau sikap) yang baru.

Konsep Dual Coding Hypothesis yang dikemukakan oleh Paivio tentang belajar menggunakan stimulus visual dan verbal (Arsyad, 2009), menekankan pada penggunaan indera ganda pandang dan dengar memberikan keuntungan bagi siswa. Adapun perbandingan perolehan hasil penelitian menggunakan indera dengar sebesar 90\%, menggunakan indera dengar 5\% dan indera lainnya 5\%. Sedangkan Dale dengan teori kerucut pengalaman merupakan elaborasi yang rinci dari konsep tiga tingkatan Bruner bahwa bahwa semakin nyata objek yang dipelajari, maka semakin konkret pengetahuan yang diperoleh siswa dan semakin tidak langsung pengetahuan diperoleh, maka semakin abstrak pengetahuan siswa (Arsyad, 2009).

Penekanan model permainan (games) inilah sebagai upaya dalam memaksimalkan aktivitas belajar secara berkensinambungan melalui interaksi antara peserta didik dengan sajian materi pelajaran dalam bentuk permainan (Darmawan, 2012). Berkaitan dengan hal tersebut, dalam proses pembelajaran, Warsita (2008) menuturkan bahwa prinsip-prinsip behaviorisme seperti keaktifan peserta didik dalam proses pembelajaran, urutan materi yang logis, program pembelajaran menggunakan konsep stimulasi, respon, faktor penguatan (reinforcement), serta umpan balik (feedback) hingga saat ini masih banyak diterapkan dalam mengembangkan program maupun media pembelajaran berbasis komputer. Adapun menurut teori belajar ini, belajar merupakan proses perubahan perilaku yang terjadi karena adanya respon terhadap situasi atau stimulus tertentu, dimana seseorang dikatakan telah belajar apabila menunjukkan perubahan perilakunya (Warsita, 2008; Rusman, 2012).

Game atau permainan adalah suatu sistem atau program dimana satu atau lebih pemain mengambil keputusan melalui kendali pada objek di dalam permainan untuk suatu tujuan tertentu (Aprilianti dkk, 2013).Pengertian lainnya, 
game merupakan aktivitas pelengkap untuk pembelajaran di kelas yang membawa efek positif dan signifikan bagi siswa (Abdullah dkk, 2012). Sedangkan game edukasi sendiri merupakan permainan atau aktivitas menyenangkan yang memuat konten pendidikan (Sari dkk, 2014; Festus \& Adeyeye, 2012), atau dengan kata lain game edukasimerupakan kombinasi antara pendidikan dengan hiburan (Panagiotakopoulos, 2011), yang dibuat untuk merangsang daya pikir termasuk meningkatkan konsentrasi dan memecahkan masalah.

Selanjutnya, terdapat beberapa kriteria dari sebuah game edukasisebagai salah satu software yang menunjang dalam kegiatan pembelajaran, diantaranya : 1) Nilai Keseluruhan (Overall Value); terpusat pada desain dan panjang durasi game, 2) Dapat Digunakan (Usability); yakni kemudahan saat digunakan dan diakses, 3) Keakuratan (Accuracy); yakni bagaimana kesuksesan model/gambaran sebuah game dapat dituangkan ke dalam percobaan atau perancangannya, 4) Kesesuaian (Appropriateness); yakni bagaimana isi dan desain game dapat diadaptasikan terhadap keperluan pengguna dengan baik, 5) Relevan (Relevance); yakni dapat mengaplikasikan isi game ke pengguna, dimana sistem harus mendukung pengguna (siswa) dalam mencapai tujuan pembelajaran, 6) Objektivitas (Objectives); yakni usaha pengguna dalam mempelajari hasil dari game secara objektif, serta 7) Umpan Balik (Feedback) (Andriansyah. 2014).

Budaya diartikan sebagai keseluruhan sistem berpikir, nilai, moral, norma, dankeyakinan (belief) manusia yang dihasilkan masyarakat. Sistem berpikir, nilai, moral, norma, dan keyakinan itu adalah hasil dari interaksi manusia dengan sesamanya dan lingkungan alamnya. Sistem berpikir, nilai, moral, norma dan keyakinan itu digunakan dalam kehidupan manusia dan menghasilkan sistem sosial, sistem ekonomi, sistem kepercayaan, sistem pengetahuan, teknologi, seni, dan sebagainya (Hakim, 2014).Dalam konteks pembelajaran berbasis budaya dalam menjagakelestarian lingkungan merupakan sumberbelajar penting di tengah lingkungan yangsemakin mengalami kemunduran kualitas.Prinsip keseimbangan dan keberlanjutan dalammengolah alam merupakan nilai penting yangharus diwariskan kepada peserta didik. Nilaitersebut lahir dari alam pikiran manusia sebagaianggota masyarakat sebagai pedoman dalammelangsungkan aktivitas sehari-hari (Efendi, 2014). 


\section{METODELOGI PENELITIAN}

Penelitian dan pengembangan berfungsi untuk menguji efektivitas atau validitas produk dan mengembangkan produk dalam arti yang luas dapat berupa memperbaharui produk yang telah ada atau menciptakan produk yang baru (Sugiono, 2015). Adapun prosedur penelitian dan pengembangan diadaptasi dari Thiagarajan dengan 4D yaitu Define, Design, Development and Dissemination. Hal ini dapat digambarkan pada gambar berikut:

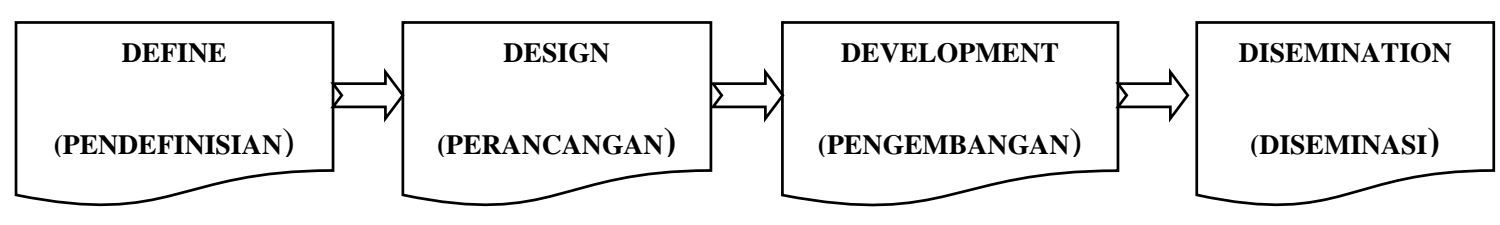

Gambar 1 Langkah-langkah penelitian dan pengembangan menurut Thiagarajan (Sugiono, 2015)

\section{Define (Pendefinisian)}

Merupakan kegiatan untuk menentukan sebuah produk yang akan dikembangkan beserta spesifikasinya. Dengan cara mengkaji produk yang akan dikembangkan untuk melihat kelebihan dan kekurangan produk yang akan dikembangkan yakni pengembangan media pembelajaran Game berbasis budaya, setelah itu melakukan studi literatur dengan cara mencari penelitian-penelitian yang berkaitan dengan studi game dan budaya serta teori-teori dan konsep-konsep yang relevan dalam pengembangan game dengan menggunakan budaya. Melakukan identifikasi permasalahan yang dialami oleh guru terkait proses pembelajaran yang dilakukan selama ini, melakukan identifikasi mengenai tingkat pemahaman siswa/i terkait local genius serta melakukan stimulus akan pentingnya melestarikan budaya. Melakukan kajian meteri bilangan pada PAUD sebagai tahap awal melakukan proses pengembangan produk.

\section{Design (Perancangan)}

Membuat rancangan produk yang bersifat menyempurnakan dan mengembangkan berdasarkan hasil kajian penelitian dan studi literature, dengan harapan produk yang dihasilkan lebih efektif, efisien dan lebih praktis sehingga menghasilkan produk awal hasil pendefinisian. Adapun langkah yang dilakukan adalah menentukan urutan bahan baik berupa mentukan konten materi bilangan 
yang yang dihubungkan dengan jenis-jenis budaya Indonesia mulai dari tokoh pewayangan memegang angka, jenis-jenis rumah ada yang dengan pemberian bilangan serta menggunakan musik-musik tradisional agar siswa/i lebih mencintai budaya Indonesia sejak dini. Spesifikasi rancangan produk inilah yang akan ditampilkan kedalam aplikasi media pembelajaran dengan menggunakan adobe flash cs6. Menentukan design awal beserta konten-konten yang terdapat didalamnya.

\section{Development (Pengembangan)}

Membuat rancangan menjadi produk dan melakukan uji validitas secara bertahap sampai menghasilkan produk yang sesuai dengan spesifikasi yang diharapkan.

\section{HASIL PENELITIAN}

Adapun produk dari penelitian dan pengembangan ini berupa Media Pembelajaran game edukasi yang berbentuk file aplikasi (.exe) disertai petunjuk penggunaan dalam bentuk file PDF. Selain itu, dilakukan pula pengambilan kesimpulan dari berbagai data yang dianalisis. Berdasarkan analisis data penilaian ahli, tanggapan praktisi/guru, dan siswa, proses dan skor capaian hasil belajar siswa; diperoleh hasil sebagai berikut : Media Pembelajaran game edukasi valid dengan rata-rata persentase $83,50 \%$, praktis dengan persentase $88,60 \%$, dan efektif dengan rata-rata persentase $88,23 \%$ serta hasil perhitungan sumbangan keberhasilan penggunaan Media Pembelajaran game edukasi pada uji coba sebesar 90,44\% (skala kecil) dan 85,19\% (skala besar). Selain itu, untuk mengukur efektivitas media tersebut juga dapat dilihat berdasarkan skor pencapaian hasil belajar siswa yang menunjukkan rata-rata di atas KKM 75 (dalam hal ini 7,5). Secara keseluruhan, rata-ratanya di atas 7, meskipun terdapat 2 siswa pada uji coba skala kecil dan 3 siswa pada uji coba skala besar yang mendapat skor di bawah 7 .

Berdasarkan hasil penelitian dan pembahasan yang telah dikemukakan, maka dapat disimpulkan bahwa Media Pembelajaran game edukasi: a. Valid dengan rata-rata persentase $83,50 \%$. Adapun persentase aspek-aspek yang berkaitan dengan validitas diantaranya : navigasi dan penggunaan (78\%), teks 
$(84,44 \%)$, tampilan $(80 \%)$, dan materi $(91,54 \%)$. b. Praktis dengan persentase $88,60 \%$ dalam aspek keterlaksanaan kegiatan pembelajaran. c. Efektif dengan rata-rata persentase $88,23 \%$. Adapun persentase aspek-aspek yang berkaitan dengan keefektifan diantaranya : motivasi $(87,33 \%)$, daya tarik $(90,80 \%)$, dan kebermanfaatan $(86,57 \%)$; serta hasil perhitungan sumbangan keberhasilan penggunaan media tersebut pada uji coba sebesar 90,44\% (skala kecil) dan $85,19 \%$ (skala besar). Selain itu, berdasarkan skor pencapaian hasil belajar siswa juga menunjukkan rata-rata di atas 7 , meskipun terdapat 2 siswa pada uji coba skala kecil dan 3 siswa pada uji coba skala besar yang mendapat skor di bawah 7 . Secara keseluruhan, pengembangan Media Pembelajaran game edukasi berbasis Adobe Flash CS6 Professional pada materi Aljabar SMP mendapat penilaian dan tanggapan yang baik dari para ahli, praktisi/guru, maupun siswa. Dengan demikian, Media Pembelajaran game edukasi dapat dikatakan layak digunakan sebagai media pembelajaran matematika SMP.

\section{SIMPULAN}

Berdasarkan hasil penelitian dan pembahasan yang telah dikemukakan, maka dapat disimpulkan bahwa Media Game edukasi berbasis budaya. Valid dengan rata-rata persentase $83,50 \%$. Adapun persentase aspek-aspek yang berkaitan dengan validitas diantaranya : navigasi dan penggunaan (78\%), teks $(84,44 \%)$, tampilan (80\%), dan materi (91,54\%).Praktis dengan persentase $88,60 \%$ dalam aspek keterlaksanaan kegiatan pembelajaran.

Secara keseluruhan, pengembangan Media pembelajaran game edukasi Adobe Flash CS6 Professional pada materi lain mendapat penilaian dan tanggapan yang baik dari para ahli, praktisi/guru, maupun siswa. Dengan demikian, Media Pembelajaran game edukasi dapat dikatakan layak digunakan sebagai media pembelajaran pada matematika.

Perlu dilakukan penelitian dan pengembangan yang lebih update. Misalnya saja dengan mengembangkan media pembelajaran berbasis Adobe Flash yang tidak hanya dapat digunakan di komputer, melainkan dapat pula dimainkan di mobile phone agar lebih praktis bagi siapa saja. 


\section{DAFTAR PUSTAKA}

Abdullah, dkk. 2012. The Impact of Video Game in Childern's Learning of Mathematics. International of Journal Social, Mangement, Economics and Business Engineering Vol 6 No 4

Ali, Muhammad. 2009. Pengembangan Media Pembelajaran Interaktif Mata Kuliah Medan Elektromagnetik. Jurnal Edukasi@Elektro. Vol 5 No. 1. Hal. 11:18.

Andriansyah. 2014. Perancangan Aplikasi Game Edukasi Menggunakan Metode Linear Congruent Method (LCM).Pelita Informatika Budi Darma Vol 6 No 1

Aprilianti, dkk. 2013. Aplikasi Mobile Game Edukasi Matematika Berbasis Android. Jurnal Script Vol 1 No 1, 1 Desember 2013

Arikunto, S. 2008. Dasar-Dasar Evaluasi Pendidikan. Jakarta : Bumi Aksara

Arikunto, S. 2009. Dasar-Dasar Evaluasi Pendidikan (Edisi Revisi). Jakarta: Bumi Aksara

Arsyad, azhar. 2009. Media Pembelajaran. Jakarta: Rajawali Pers.

Cahyadi, Dede. 2014. Pengembangan Media Pembelajaran Berbasis Flash pada Mata Pelajaran IPA Terpadu Pokok Bahasan Wujud Zat.

Danoebroto, Sri Wulandari. 2012. Model Pembelajaran Matematika Berbasis Pendidikan Multikultural. Jurnal Pembangunan Pendidikan : Fondasi dan Aplikasi. Vol. 1 Hal. 94:107.

Darmawan, D. 2012. Pendidikan Teknologi Informasi dan Komunikasi. Bandung : PT. Remaja Rosdakarya

Efendi, Agus. 2014. Implementasi Kearifan Budaya Lokal pada Masyarakat Adat Kampung Kuta sebagai Sumber Pembelajaran IPS. Jurnal Sosio Didaktita, Vol. 1, No. 2

Festus \& Adeyeye. 2012. The Deveopment and Use of Mathematical Games in Schools. Paper of Mathematical Theory and Modelling Vol 2 No 8

Hakim, Dhikrul. 2014. Implementasi Pendidikan Budaya dan Karakter Bangsa dalam Kurikulum Tingkat Satuan Pendidikan (KTSP) di Sekolah.Jurnal Studi Islam Vol. 5 No. 2 ISSN 1978-306X; 145-168

Hardini., \& Puspitasari. 2012. Strategi Pembelajaran Terpadu (Teori, Konsep, \& Implementasi). Yogyakarta : Familia

In'am, Ahsanul. 2015. Menguak Penyelesaian Masalah Matematika, Analisis Pendekatan Metakognitif dan Model Polya. Malang: Aditya media publishing.

Kachepa \& Jerre. 2014. Implementation of Mobile Games for Mathematics Learning : A Case of Namibian School. International Journal of Scientific Knowledge Vol5No5

Katmada, dkk. 2014. Implementing a Game for Supporting Learning in Mathematics. The Eectronic Journal of e-Learning Vol 12 Issue 3

Ke, Fengfeng. 2008. A Case Study of Computer Gaming for Math : Engaged Learning from Gameplay?. Computers and Education, Journal Homepage www.elsevier.com/locate/compedu)

Laksana dkk. 2013. Keefektifan Model Pembelajaran STAD Disertai Permainan MAM Terhadap Kemampuan Pemecahan Masalah Siswa Kelas X. Jurnal Kreano. Vol. 4 No. 2. Hal. 197:203. 
Masykur \&Fathani. 2007. Mathematical Intelligence. Yogyakarta : Ar-Ruzz Media

Mavrotheris. 2012. Game-Enhanced Mathematics Learning for Pre-Service Primary School Teachers. ICICTE Proceedings. Cyprus : European University Cyprus

Muslimin dkk. 2012. Desain Pembelajaran Pengurangan Bilangan Bulat Melalui Permainan Tradisional Congklak Berbasis Pendidikan Matematika Realistik Indonesia di Kelas IV Sekolah Dasar. Jurnal Kreano. Vol. 3 No. 2. Hal. 100:112.

Panagiotakopoulos. 2011. Appying a Conceptual Mini Games for Supporting Simple Mathematical Calculation Skill : Student's Perceptions and Considerations. World Journal of Education Vol 1 No 1

Pareto. 2010. A Teacheble Agent Game for Elementary School Mathematics Promoting Causal Reasoning and Choice. APLEC Workshop Proceedings

Park. 2012. Relationship Beetwen Motivation and Student's Activity in Educational Game. International Journal of Grid and Distributed Computing. Vol 5 No 1

Purwanto. 2007. Metodologi Penelitian Kuantitatif untuk Psikologi dan Pendidikan. Yogyakarta : Pustaka Pelajar

Rachman, H \& Rusdiansyah A. 2012. Pengembangan Rancang Bangun Game Edukasi Logistik "Stowagame” Mengenai Penataan Kontainer di Bay Kapal. Jurnal Teknik Industri Vol 13 No 1

Rusman. 2012. Belajar dan Pembelajaran Berbasis Komputer : Mengembangkan Profesionalisme Guru Abad 21. Bandung: Alfabeta

Sadiman, Arief. S, dkk. 2010. Media Pendidikan Pengertian, Pengembangan dan Pemanfaatan. Jakarta:Rajawali Pers.

Safitri, Melani dkk. 2013. Pengembangan Media Pembelajaran Matematika Pokok Bahasan Segitiga Menggunakan Macromedia Flash untuk Siswa Kelas VII SMP. Indonesian Jurnal on Computer Science. Vol. 10 No. 3. Hal 28:35.

Sanjaya, W. 2012. Perencanaan dan Desain Sistem Pembelajaran. Jakarta : Kencana Prenada Media Grup

Sari, W, dkk. 2014. Pengembangan Game Edukasi Kimia Berbasis Role Playing Game (RPG) pada Materi Struktur Atom sebagai Media Pembelajaran Mandiri untuk Siswa Kelas X SMA di Kabupaten Purworejo. Jurnal Pendidikan Kimia (JPK) Vol 3 No 2 Universitas Sebelas Maret

Serin. 2011. The Effects of The Computer Based Instruction on The Achievement and Problem Solving Skills of The Science and Technology Students. The Turkish Online Journal of Educational Technology Vol 10 Issue 1

Shadiq, Fadjar dan Mustajab, Nur Aini. 2011. Penerapan Teori Belajar dalam Pembelajaran Matematika di SD. Kemendiknas.

Shafie \& Ahmad. 2011. Design of The Learning Module for Math Quest: A Role Playing Game for Playing Numbers. International Conference on Communication Engineering and Networks Vol 19

Shin, dkk. 2012. Effects of Game Technology on Elementary Student Learning in Mathematics. British Journal of Education Technology Vol 43 No 4 
Sugiyono. 2011. Metode Penelitian Kuantitatif Kualitatif dan $R \& D$. Bandung : Alfabeta

Suprapti. 2015. Meningkatkan kualitas pembelajaran matematika pada topic dimensi tiga melalui pembelajaran kooperatif tipe STAD dengan pendekatan saintifik realistic siswa kelas X-1 SMAN 16 Makasar. Jurnal Daya Matematis. Vol. 3 No. 3, hal 353-361.

Triyanto, Eko. 2013. Peran Kepemimpinan Kepala Sekolah dalam Pemanfaatan Media Pembelajaran sebagai Upaya Peningkatan Kualitas Proses Pembelajaran. Jurnal Teknologi Pendidikan. Vol 1, No 2. Hal 226-238.

Warsita. 2008. Teknologi Pembelajaran: Landasan dan Aplikasinya. Jakarta : Rineka Cipta

Wulandari, Raifi, dkk. 2014. Pengembangan Perangkat Pembelajaran Berbasis Pembelajaran Matematika Realistik Pokok Bahasan Kubus dan Balok. Jurnal Pancaran. Vol. 3, No. 1, hal 131-140. 